\title{
A College Knowledge Outreach Program for Latino Immigrant Parents: Process and Evaluation
}

\section{Laura M. Gonzalez, PhD \\ The University of North Carolina at Greensboro}

\begin{abstract}
As Latino immigrant families adjust to life in the U.S., they may experience individual and systems level barriers to meeting their children's educational planning needs. In emerging immigrant communities, schools and social service agencies may not have all the resources and structures needed to serve Spanish-speaking parents. Thus, researchers and practitioners may need to consider partnership models to meet the needs of marginalized Spanish-speaking families. The article describes three stages in a community-based college knowledge educational outreach program for Latino parents: (1) needs assessment; (2) collaboration/implementation; and (3) evaluation. The educational outreach program was created and piloted for 27 Latino immigrant parents in two settings (middle school and community agency). The Bryan and Henry (2012) model for collaborative outreach for underserved populations was applied post-hoc to compare the pilot program with an ideal framework and identify possible improvements to the educational outreach program for Latino parents. Implications for program content and the process of community partnering are discussed.
\end{abstract}

Keywords: Latino immigrant parents, outreach programming, partnership model 


\section{Introduction}

According to census data from 2012, roughly 18.8 million first generation immigrants from Latin American countries live in the U.S., along with 34.1 million native born Latinos (Krogstad \& Lopez, 2014). These new arrivals tend to have fewer resources. For example, $26 \%$ of Mexican immigrants who migrated to the U.S. in 2013 were living in poverty, 31\% were proficient in English, and 6\% had a bachelor's degree (Gonzalez-Barrera, 2015). Although most of Latino families who live in the U.S. reside in California, Texas, New Mexico, Arizona, Illinois, Florida, and New York (i.e., traditional gateway states), the states with the largest increases in Latino population from 2000-2010 were South Carolina, Alabama, Tennessee, Kentucky, Arkansas, North Carolina, and Maryland (Immigration Policy Center, 2012). These emerging immigrant communities may be limited in their support systems and structures, and often are building capacity to respond to newcomers from other countries (Wainer, 2004). Thus, there may be an inherent disconnect in emerging immigrant communities between the strategies and resources in place by the service providers and the needs and barriers experienced by the newcomers.

There are many ways that this disconnect can impact immigrant families, but the current article will focus on education. Educational opportunity is one of the key motivations for families to immigrate to the U.S. Furthermore, Latino immigrant parents can provide tremendous motivation and emotional support for their children in terms of educational goals, but may have fewer tools to enable them to provide instrumental support for planning (Gonzalez, Villalba, \& Borders, 2015). Previous researchers have suggested that schools may need to revise their assumptions about what immigrant parents and families know about educational processes and planning in the U.S. or how best to communicate with newcomers (Auerbach, 2007; Tornatsky, Cutler, \& Lee, 2002; Walker, Ice, Hoover-Dempsey, \& Sandler, 2011). Several researchers have documented that Latino immigrant parents are less likely to participate in school based parental involvement activities (e.g., PTA meetings, volunteering, attending meetings with school counselor) (DeGaetano, 2007; Delgado-Gaitan, 1991) and more likely to follow their cultural scripts about home-based involvement with their children (Mena, 2011). However, schools in emerging communities can build capacity for educational engagement with Spanish-speaking parents by building on those strengths and addressing challenges or barriers.

There are many potential barriers to access of school services by adults in immigrant families, including lack of linguistically and culturally appropriate outreach, restrictive policies regarding eligibility for services, and cultural norms held by immigrant families about defining problems and identifying relevant resources (Auerbach, 2002; Van Velsor \& Orozco, 2007; Zarate, 2007). This list includes both individual level barriers (e.g., acculturation to new norms or familiarity with a new system of service providers) and systems level barriers (e.g., monolingual resources, restrictive policies). Thus, counselors, educators, or advocates will need to consider ways to promote access to and evaluate effectiveness of school-based services for Latino immigrant families, including strategies for proactive outreach or advocacy with these communities (Auerbach, 2004; Delgado-Gaitan, 1991; Mellin, Belknap, Brodie, \& Sholes, 2015; Suarez-Orozco, Onaga, \& Lardemelle, 2010). Effective outreach should attend both to content/information and process/collaboration. 
One useful model for the process of conducting outreach or generating partnerships with disenfranchised or vulnerable communities has come from the school counseling literature. Bryan and Henry (2012) emphasized collaboration, empowerment, and social justice in their process model for establishing effective school-family-community partnerships. The conceptual model includes seven steps, which are "(a) preparing to partner, (b) assessing needs and strengths, (c) coming together, $(d)$ creating shared vision and plan, (e) taking action, ( $f$ ) evaluating and celebrating progress, and (g) maintaining momentum" (Bryan \& Henry, 2012, p. 411).

Given the value placed on education in immigrant families, the informational needs of Latino parents who are newcomers to the U.S., and the utility of community outreach, this praxis-based article will provide an example of a Spanish-language educational outreach program for parents (see Figure 1).

Figure 1. Steps in creating content of outreach program
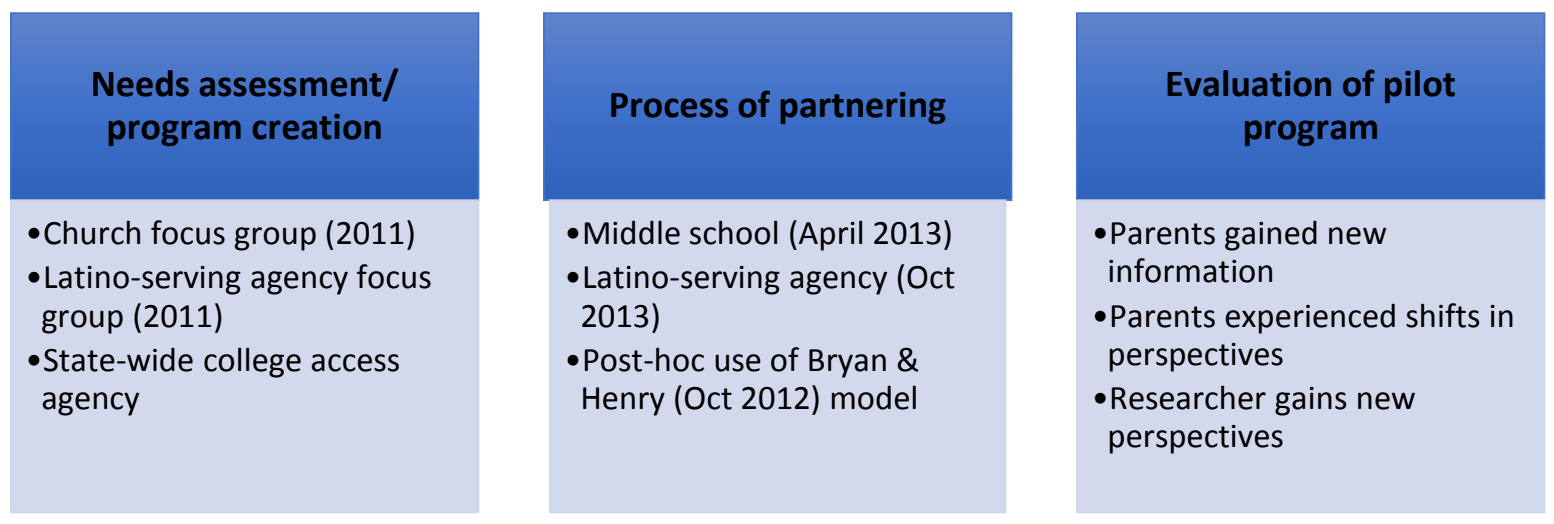

The article is organized around the three phases of the project: (1) doing a community-based needs assessment to inform program content; (2) using the Bryan and Henry (2012) conceptual model to evaluate the partnership process that was implemented; (3) and reviewing program evaluation data from participants to draw initial conclusions about program effectiveness. Because the Bryan and Henry partnership model was published after this project had already begun, it was not used as a guide to collaboration (as it ideally would have been), but rather was used post-hoc as a way for the researcher to learn and improve the project. This article represents the concept of praxis - a cycle of activity or experience, critical reflection about the activity, and renewed practice after integrating the lessons learned (Kolb, 1984).

Thus, the purpose of this article is twofold. The researcher will describe initial steps in a community-based research project, which is part of the continuum of participatory or community-engaged research, but represents an earlier developmental phase of such research designs (Office of Community Engagement, 2012). The researcher will elaborate on "lessons learned" along the way, in the hopes that others interested in models of community-engaged research would benefit from both the strengths and weaknesses of the current implementation. 
The second goal is to situate the program in the content-based literature of college knowledge outreach for Latino immigrant parents and note its contributions to practice in an emerging immigrant community (as contrasted with most examples of outreach for Latinos, which are based in traditional gateway states in California, Texas, Florida, and New York).

\section{College Knowledge Outreach Program}

A group of counselor educators interested in promoting educational access for youth in immigrant families began a research-to-practice group with the intention of learning about the strengths and needs of immigrant families with respect to education, the practices of the educational systems in the local community, and the gaps or opportunities between them. Our goal was to understand the lived realities of the families and support the educational community and provide guidance to immigrant families. The researchers hypothesized that Latino immigrant families were not receiving similar assistance and resources from school counselors as other families (given the structural limitations of being in a new immigrant community without translators, interpreters, or key cultural brokers available for assistance). Thus, we embarked on a needs assessment. The research group included two bilingual individuals who could communicate with Spanish-speaking community members (including the author and a collaborator). The research group also had a network that included bilingual service providers in the community.

The needs assessment and program creation phase was inductive in nature, and included (a) focus groups with Spanish-speaking parents at a Latino-serving church and a Latino-serving community agency and (b) review of resources and materials held by a state-wide college access clearinghouse (College Foundation of North Carolina, n.d.). Thus, the topics of the program had a foundation in standard college planning materials (e.g., high school coursework, types of colleges, aspects of the application and financial aid processes), but were modified to be appropriate to the population given the focus group data. After the 6-week outreach program was created and piloted with immigrant parents at the middle school $(N=18)$ and at the Latinoserving community agency $(N=9)$, preliminary feedback from the participants and partnering sites was gathered and is shared as pilot program evaluation data. The three groups that form the set of stakeholders for this project included the university, community entities, and immigrant families.

\section{Initial Needs Assessment}

Assessment should involve as many perspectives as possible, and should not be limited only to a deficit perspective. From the community-engaged research lens, the needs assessment must include direct input from the individuals who are affected by the problem (Office of Community Engagement, 2012). In the current example, the community assessment phase began with a conversation with bilingual service providers about perceived educational needs of Latino immigrant families, including the staff at the Latino-serving community agency (LCA), a local Latino church leader, and a state-wide educational advocate for Spanish-speaking families. Two focus groups were planned and conducted with samples of Spanish-speaking parents from the LCA and the local church (Gonzalez et al., 2015). From the focus group participants, the 
counselor educators sought to learn about the following: (a) aspirations about education held by Latino immigrant parents; (b) their perceptions of the availability of culturally and linguistically relevant resources; and (c) resources available for both informational and financial resources to address unmet needs.

Findings from the two focus groups conducted by the researchers identified who were the bilingual service providers and role models who were supporting educational pathways of Latino family members and the limited interactions family members had with English-only programs and resources (Gonzalez et al., 2015). The researchers heard immigrant parents reflect on education as the best legacy they could give to their children in the U.S. In addition, the researchers learned that Latino immigrant families valued the importance of transmitting knowledge about their cultural heritage and becoming role models, so that their family could withstand challenges and that their children could learn to be resilient in the face of difficulty. Parents also conveyed their worries about their children's futures and limits to their ability to help (e.g., struggling with legal status, economic burdens, language barriers, and little access to information). Parents expressed a desire to do more to help their children beyond monitoring their behaviors, keeping them on a productive path and providing emotional encouragement to reach their goals. Parents knew that future educational options required planning ahead, but they did not know what specific steps were needed to initiate that plan. When they tried to interact with school personnel to improve their capabilities to guide their children, the experiences were often painful and discouraging. At times, the schools were experienced as unwelcoming or impenetrable systems by immigrant parents.

\section{Program Creation}

After considering the themes from the two parent focus groups and reading existing literature about educational interventions with Latino immigrant parents (e.g., Auerbach, 2002; 2004), the researchers partnered with a state-wide educational access agency (CFNC), which sponsors a comprehensive website to help students and families plan for college and career, apply to college, and find resources to pay for their education (College Foundation of North Carolina, n.d.). The website content is primarily in English, with a few sections translated in Spanish; however, many immigrant parents are unaware of this resource. The research team then worked with the agency to combine the data streams to create the content for the outreach program (Borders, Hines, Gonzalez, Villalba, \& Henderson, 2011).

\section{Process of Collaboration}

The resulting outreach program was implemented before the principal researcher became aware of the Bryan and Henry (2012) model, but the current study describes the steps of their partnership model to illustrate how the researcher's initial experience with the collaboration process could have been improved. Thus, this section is organized by the stages of the Bryan and Henry (2012) model, with commentary about the degree of consistency between the researcher's program and the ideal represented by the model. 


\section{Preparing to Partner and Assessing Needs/Strengths}

The Bryan and Henry (2012) model begins with a service provider (e.g., practitioner, educator, or community partner) gathering information to describe the groups present in the community and any constraints to the provider's ability to partner with them. This model indicates that if the way forward to partner is open or can be opened, then a needs and strengths assessment can be conducted. Due to the value for empowerment of the community, the model clearly seeks to avoid a deficit perspective in the assessment phase and to be as inclusive as possible in inviting participation in the assessment. In the current example, the assessment phase was described and evaluated in the previous section. While immigrant community voices were part of the needs assessment, the process could have been more fully community-engaged by including those parents as leaders or decision makers in the early phases of partnering.

\section{Coming Together and Creating a Shared Vision}

Bryan and Henry (2012) recommends convening all stakeholders for an initial meeting to establish a democratic and equitable process and discuss strategies to meet community needs. The stakeholder team could include leaders in the identified agencies/schools/organizations, cultural brokers in the population of interest, and members of the intended audience. In the current example, initial meetings were conducted separately with a state-wide agency dedicated to educational access and outreach, including the Spanish-services coordinator, and with leaders in the partnering schools and community agencies. The first set of meetings with the state-wide agency were to discuss and come to consensus on relevant content of an outreach curriculum, review literature about effective outreach to Latino immigrant parents in other regions, and learn from the experiences of the existing Spanish-services coordinator. The second set of meetings included leaders at the intended outreach settings (e.g., administrators, school counselors, a parent advocate, and ESL teachers at the middle school, and service coordinators at the LCA). The researcher learned that Latino parents were strongly motivated and interested in receiving information about educational planning.

The researchers heard about needs of Latino immigrant parents and children already receiving services at both locations from the program coordinators (e.g., basic English classes at the school, parenting strategies group at the LCA). The principal researcher then shared our preliminary outreach program with the program coordinators to see if it could help meet needs and considered ways to adapt it to increase relevance, such as (a) having local Latino immigrant parent or student role models speak about their experiences; (b) including more specific information about local options for post-secondary education; (c) having bilingual school personnel introduce themselves as resources and bring translated documents about relevant programs and opportunities; and (d) having current information on local policies that affected this population (e.g., under which circumstances can students with undocumented parents apply for university admission or financial aid). Thus, the process of creating a shared vision was iterative, with initial needs assessment from the Latino parent focus groups leading to creation of the outreach program content and subsequent opportunities for comment and feedback from partnering organizations. 
Upon reflection, possible improvements to the process could include asking parents for their input on the planned outreach program in terms of content and logistics. This would increase their visibility, their buy-in to the program, and the chances that they could participate (i.e., identify and eliminate barriers). The researchers could also have consulted more consistently with a formalized leadership team of community partners to create a shared vision throughout implementation.

\section{Taking Action: Recruitment and Implementation}

In the Bryan and Henry (2012) model, taking action includes delegation of tasks to members of the leadership team, moving forward with the planned timeline of activities, and including media coverage to highlight the partnership. The current outreach program was a pilot version, so it was time-limited, had little media coverage, and a more centralized structure. This divergence from the partnership model and from norms of community-engaged research will be discussed in the limitations section. Community partners assumed the task of publicizing the outreach program, recruiting interested parents, and preparing a space for the six sessions. The facilitators assumed responsibility for preparing session content and materials, including guest speakers, and implementing program evaluation. University IRB approved the study as exempt, and verbal assent rather than written consent was utilized due to the characteristics of the participant population. Implementation of the program will be described briefly in the section of the article entitled "Evaluation of the outreach program."

\section{Evaluating, Celebrating, and Maintaining Progress}

Bryan and Henry (2012) emphasized both evaluation of program outcomes and evaluation of the partnership process, as well as celebration of the accomplishments of all parties involved. In the current example, program evaluation feedback was solicited from both parents and community partners. Partner feedback included implications for the collaborative process. The partners reflected that the beneficial aspects of the program had been (a) seeing the parent participants and their children discuss future academic plans together after the outreach program; (b) observing the motivation and dedication of the parent participants in terms of attendance and participation; (c) observing how the parents' sustained participation motivated helpful responses from school staff and administrators; and (d) noticing how the bilingual materials and provision of child care and food facilitated that participation. The partners noted that improvements could still be made in terms of (a) sustaining or expanding such outreach programming; (b) continuing to assess needs and interests of local parents to have relevant offerings; and (c) connecting the Latino immigrant parents to other support entities in the community.

The parents in the school setting celebrated their success by collectively organizing a potluck dinner for the final session. In addition, the parents have continued to stay in touch with the presenters and the school contacts as they move forward with educational planning for their children. The parents at the LCA requested a campus tour of the university where the counselor educators are located. In both cases, the parent community became more aware of their common struggles and strengths and formed an internal support group. 
The last stage in the Bryan and Henry (2012) partnership model is maintaining relationships with the partnering entities. Although the pilot outreach program described was finite in nature, it has led to ongoing partnerships and to a new grant funded opportunity to initiate similar outreach in a nearby county. The researchers are maintaining connection by planning for a campus visit for the LCA parents. This partnership also has helped to bring more resources to the middle school, including bilingual mental health services one day a week, a four sessions Spanish-language parent academy addressing both academic and mental health topics, and consultation with the school counseling staff and administrators regarding Latino immigrant family needs. Overall, the post-hoc application of the Bryan and Henry (2012) model to the outreach program has highlighted some strengths (e.g., attending to immigrant parent perspectives, collaborating with community partners) and some areas for continued growth (e.g., expanding the collaboration to leadership and decision making, maintaining momentum in the partnership).

\section{Evaluation of the Pilot Programs}

The college knowledge outreach program for Latino immigrant parents was piloted with 27 participants in total at the middle school and LCA. The topics discussed were as follows: (a) understanding your child's interests; (b) improving the high school experience; (c) finding the college that best fits your child; (d) the admissions process; (e) the financial aid process; and ( $f$ ) following the path forward (Villalba, Gonzalez, Borders, \& Hines, 2014). These topics were related to the community needs assessment in that parents had described their isolation from English only resources and their lack of knowledge of existing Spanish language resources, their motivation to help their children achieve educational goals, and the current limits to their ability to help with instrumental tasks (Gonzalez et al., 2015). The current outreach program was implemented in an educational curriculum format, with 60-90 minute sessions in Spanish occurring once a week for six weeks. The presenters were two White female educators who had acquired Spanish as a second language; both had been involved in the initial development phases of the program. A bilingual process observer was present each week at the middle school pilot to help the presenters monitor participant reactions and provide suggestions for improving implementation. At the LCA, the bilingual staff person was present for all sessions and provided helpful feedback. Guest speakers with a relevant connection to the participants (i.e., similar cultural experiences, examples of successful implementation of college preparation tasks, local service providers) were present for several of the sessions at each location.

\section{Methods}

\section{Participants}

A total of 27 parents (18 parents from the middle school and 9 parents from the community) participated in this program; they completed initial demographic forms and attended all six sessions. All study participants were immigrants, predominantly from Mexico $(n=21)$, Colombia $(n=2)$, Cuba $(n=1)$, Uruguay $(n=1)$, and unspecified $(n=2)$. Most were women $(74 \%)$, and their ages ranged from 32-50, with one grandparent who was 70 years old in attendance. Their 
occupations were mainly labor-based (i.e., seamstress, factory employee, clerk, mechanic, construction worker). In terms of receiving formal education, 19 had not completed high school, 3 had a technical certificate, and 5 had completed a post-secondary degree (two or four year).

\section{Results}

\section{Parent Feedback}

Prior to the first session, the parent participants responded to an open-ended question on the demographic form, which was "What are the main worries of the parents about helping their children to prepare and apply to college?" The concerns they listed included: (a) limitations in English fluency; (b) limited access to computer-based information; (c) lack of available bilingual resources; (d) lack of certainty of who to ask for help; (e) cultural barriers to understanding the educational system; and ( $f$ ) concerns about child's eligibility for post-secondary study (e.g., grades, legal status, financial status). These concerns represent the identified needs in the words of the parent participants.

Written qualitative feedback from parent participants also was gathered after the final session. Since this was a pilot study, the researchers were most interested in participants' open-ended perceptions of the outreach program. Parents in attendance at the last session were given a survey with three prompts: (1) What new information did you learn in this workshop? (2) What was surprising or impactful to you from the workshop? and (3) How could we improve the workshop for the future? Brief qualitative feedback was gathered in Spanish and translated into English by the author, with a validation check by one of the bilingual program presenters.

Parents at both sites gave similar responses to the questions. One theme that emerged was about new information that they had learned and resources they had acquired. Parents identified specific college planning information that was beneficial to them (e.g., scholarships or financial aid forms, online resources, the "nuts and bolts" of the application process, an understanding of the SAT and ACT, and the connection between college degree types and careers). Parents specifically found it impactful to learn about the application and financial aid process and resources that exist to help with that task, including special resources for families with an undocumented member.

The second theme took on a more personal or affective note about the parents' role in college planning with their children. Several parents offered general reflections about new perspectives they had gained, such as "there are people who can help us, both the child and the parent," "if a person wants to and puts all their determination into it, the child can achieve his dreams and have a better future," and "we have to support our children and not be afraid." Three parents stated learning about financial aid resources meant that sending their child to college was indeed possible. Similarly, another parent mentioned, "Something I didn't know that there are many kinds of help, my husband and I thought that it was very difficult to send our kids [to college] because it is very expensive, but we learned that it can be done." 
In the final theme, parents expressed appreciation for the relationships and models that they observed during the program. Five participants mentioned that a guest speaker with DACA (Deferred Action for Childhood Arrivals) status was very impactful. His testimony and that of other guest speakers showed parents that "with effort and dedication, a person could go far." Participants also found the fact that the outreach program was delivered in Spanish by nonnative speakers to be noteworthy. Five expressed appreciation for the bilingual presenters' dedication and genuine interest in the parent's concerns. One stated, "The interest of the teachers surprised me, how they showed us with lots of caring how to encourage our children to keep studying." Another wrote, "Knowing that we can count on you was the most important thing." Finally, two participants mentioned the benefit of hearing the stories of the other parents in the workshop, as they had shared similar concerns and aspirations for their children.

In terms of what could be improved for the future, almost every participant said that the workshop was very informative and beneficial. The most common suggestion related to increased advertisement. Participants suggested reaching out to Hispanic/Latino parents' work places, increasing the number of meetings, and sending flyers home with students. As one participant commented, "I thought the workshop was perfect; it already had all the information that we needed. The only thing I saw was there wasn't enough publicity."

\section{Discussion and Implications}

This praxis-based article describes three stages of a Spanish-language educational outreach program for Latino immigrant parents: a needs assessment, partnering/implementation, and evaluation (see Figure 1). Along a continuum of community-engaged research models, our project was not fully community participatory (e.g., with community members functioning as coinvestigators who play a role in study design, implementation, data collection, and interpretation) but also was not fully traditional (e.g., researcher driven without any interactions with community members). Instead, it was community-based, in that community members were involved with the researchers in the needs assessment, gave feedback on the program contents and structure, were part of the implementation team, and helped to interpret findings and suggest improvements (Office of Community Engagement, 2012). The Bryan and Henry (2012) model for school-family-community partnerships also would have suggested more emphasis on community participation in the leadership team, so this pilot remains an approximation of the ideals of community engagement.

However, there are still important contributions made by this outreach program and the lessons learned throughout. One set of implications is for outreach programs with similar content, seeking to share college knowledge with Latino immigrant parents and to encourage their engagement with their children in both affective and instrumental support of educational goals. The second set of implications is for the process of forming a partnership to benefit a vulnerable group, and bringing together stakeholders in a collaborative social action. 


\section{Implications for Content}

The existing literature on college knowledge outreach programs for Latino immigrant parents is based in traditional gateway states like California or Texas (e.g., Auerbach's studies), which typically means these communities have existing systems and structures in place to support immigrant families. In emerging immigrant communities, like the one where the current outreach program was implemented, schools may not have full time bilingual teachers or interpreters, or documents may not be translated into the language preferred by some parents (Wainer, 2004). Agencies like the LCA in the current example are few and far between, and are stretched thin trying to respond to the needs of immigrant families with few good options for referrals or resources. Immigrant families themselves may experience some isolation, as they do not see a large ethnic enclave with which to integrate upon arrival (Gonzalez et al., 2015). Thus, an outreach program in an emerging immigrant community has fewer existing supports to rely upon and is addressing needs in a vacuum (Bohon, MacPherson, \& Atiles, 2005).

On the other hand, an outreach program in an emerging immigrant community has great opportunity to make an impact. First, the parent participants demonstrated their interest in the topic by their sustained attendance over six weeks and by their qualitative feedback. It is possible that their motivation for attending this outreach program stemmed from not having many other outlets to acquire this educational information in Spanish, and from valuing education as important to their children's future opportunities in the U.S. Second, the community sites (specifically the school) responded to the parents' motivated behavior with increased efforts to promote educational access for the Latino immigrant community (e.g., translating documents into Spanish, continuing to offer free English classes for parents). Discussions with stakeholders included potential systems-level responses for common immigrant stressors (e.g., legal status, language acquisition, acculturation), thus helping to build capacity in a school and an agency that had already shown their commitment to immigrant families.

Consistent with previous studies, when immigrant parents receive information in a manner and setting that is conducive to their learning and that respects their cultural strengths, they become more confident advocates for their children, more motivated and proactive participants in educational planning, and able to take greater leadership roles (Auerbach, 2011). Existing literature also underscores the importance of empowering parents, increasing their collegerelevant social capital networks and role models, viewing parents as capable collaborators and leaders, and providing advocacy support when needed (Auerbach, 2004; Delgado-Gaitan, 1991; Jasis \& Ordonez-Jasis, 2012; Pstross et al., 2016). In many cases, parental outreach programs have been paired with college access programming for the students, such that post-secondary aspirations would be supported from multiple angles. Past studies also pointed toward the value of a community participatory stance in further outreach efforts (Jasis \& Ordonez-Jasis, 2012; Pstross et al., 2016). The current study contributes to the existing literature in that it is modeled after partnering with a college access agency in terms of content. For researchers in states without a college access agency, the author recommends the Spanish-language resources provided by The College Board and other national entities. 


\section{Implications for Process}

The research team's ability to deliver this program to immigrant community members would have been diminished if the principal researcher had not partnered collaboratively with the school and the LCA. The middle school had started outreach to their Latino immigrant parent population prior to our involvement by offering free English classes, and the LCA was actively sought out by Latino community members due to its unique niche as a Latino serving United Way agency. The trust that the immigrant parent participants already had in the ESL teachers and the LCA staff members built a bridge between them and the university, allowing us to interact with them in a place that was familiar and comfortable for the parents. The potential for having the same participant turnout if we had hosted the program at the university was lower, particularly for a vulnerable population. Thus, utilizing the partnership model in advance and taking the time needed to build strong collaborative relationships would be highly recommended. In the current study, places where the Bryan and Henry (2012) model could have strengthened the outreach program are noted so that future research teams may benefit from our experience.

Empowerment of parents as informed, capable, and motivated participants is a key outcome (Auerbach, 2004; Jasis \& Ordonez-Jasis, 2012; McLester, 2011; Pstross et al., 2016). Bryan and Henry (2012) included social justice, empowerment, strengths-based approach, and democratic collaboration as guiding values in their model; the researchers sought to incorporate these values in the current program to the extent possible. Presenters consistently emphasized the key role that parents have in their children's lives and appreciated their strengths as they continued to motivate, encourage, and assist their children in a new cultural context. However, involving immigrant parents as leaders in the conceptualization, planning, implementation, and evaluation of the program would model that message in a much stronger way. Parent leadership could also be a key in maintaining momentum and continuing the outreach, which was an area for growth of the current initiative.

Researchers or educators must also consider what social justice or advocacy role (if any) they are willing to play in the community, as creating opportunities for underrepresented parents to participate means making the existing social structure visible to the participants and being willing to request relevant adaptations from the social structure (Griffin \& Steen, 2011). For example, school personnel were willing to translate materials for the parents that had previously been available only in English, and the LCA sponsored an extra session about DACA eligibility with legal counsel present. Such advocacy is particularly important in cases where participants face daunting social barriers (e.g., undocumented status) and can benefit from guidance and collaboration with service providers familiar with the systems they need to access (Storlie \& Jach, 2013). The outreach program coordinators also should be attentive and responsive to systemic barriers to participation among the relevant community members (e.g., lack of transportation or child care, lack of existing trust with institutions like schools) (Gonzalez et al., 2015) as well as among the community partners and program leaders/facilitators themselves (e.g., lack of knowledge, confidence, or experience; limited communication strategies or bilingual resources; 
and political constraints of institutions) (Griffin \& Steen, 2011). The leadership team in the partnership model is an excellent place to consider what adaptations or advocacy skills are necessary to effectively serve the population of interest (Bryan \& Henry, 2012).

\section{Limitations and Conclusions}

Some limitations of our outreach program include the post-hoc application of the Bryan and Henry (2012) model, the European ethnicity of the bilingual presenters, the reliance on brief qualitative program evaluation alone, and the limited nature of the program pilot. In addition, the decision of the researcher to adopt community-based strategies as opposed to fully community-engaged or participatory research strategies (e.g., allowing community members to be full participants in the research team, including selecting topics and issues for focus, designing the study, collecting the data, and collaborating in the interpretation and dissemination of the data) could be seen as a limitation by some. The researchers prefer to consider these approaches as points on a continuum with differing types of utility for various projects and researcher skill sets (Office of Community Engagement, 2012).

In comparing the actual outreach program developed in 2011 to the ideal model of creating a collaborative partnership (Bryan \& Henry, 2012), several limitations of our implementation are apparent. The current outreach program was in a pilot version, so it was time-limited, had little media coverage, and a more centralized structure. In future outreach programming or partnerships, the researchers could attend more carefully to the phase of coming together in a sustained way to create a shared vision. While the team did seek out immigrant Latino parent community members and service providers and incorporate their perspectives into our outreach program, we may have missed some opportunities to share leadership and build capacity by involving those community members in a more significant and structured way. This stance may also relate to the way the researchers are maintaining relationships after the outreach program ended; we continue to be involved with the partners, but in a less consistent or sustained way than described by the Bryan and Henry (2012) model (e.g., having a 1-year, 3-year, and 5-year plan for the partnership, a timeline for implementation, and specific shared responsibilities for tasks). The difference could be summarized as working with community members to inform the project as compared to allowing them to directly shape the project, as in community based participatory research paradigms (Bryan \& Henry, 2012; Office of Community Engagement, 2012). There are advantages and disadvantages to each approach, but allowing community members to share in decision-making could be more empowering.

Building collaborative community partnerships can be complex and time-consuming, so another limitation could be the amount of time and resources available to devote to building and maintaining key relationships. Partnerships must often be formed slowly over time, as communication allows for effective understanding to emerge and similarities and differences in perspective to become evident. For example, parental involvement might mean something different in the U.S. educational context than it means to immigrants who are referencing the norms for involvement in their home country (Dotson-Blake, 2010). A benefit of collaboration can be dividing the work among many hands. A drawback to collaboration can be differing goals and objectives among partners. For example, counselors working in schools will need to 
consider the priorities of the leadership of the school system as well as the priorities of the community members, and be adept at communicating when there are differences in vision and needs. Ultimately, the only way to transform the systems we work in is to attend to multiple stakeholder voices and collaborate in a meaningful way to build a new vision that goes beyond our limited view of the system we work in (Mellin et al., 2015).

In terms of future research possibilities, the outreach program could be adapted depending on the level of educational fluency of the immigrant parent participants. Some Latino immigrants, for example, have college degrees from their home countries and might like to move beyond the basics to a more detailed understanding of post-secondary education in the U.S. In addition, the Bryan and Henry (2012) model is relatively recent; future research can still illuminate the strengths and opportunities of this partnership model. One obvious strength of the Bryan and Henry model is its focus on process and collaboration, which allows researchers and practitioners with interests in different populations or content areas to adopt it for practice. The "lessons learned" in the current study only underscore the way that a suitable model for partnerships and outreach can strengthen community-based research collaborations when identified and used in advance.

\section{Author Contact Information}

Correspondence concerning this article should be addressed to Laura M. Gonzalez, PO Box 26170, 1300 Spring Garden Street, University of North Carolina at Greensboro, Greensboro, NC 27402 (e-mail: LMGONZA2@uncg.edu). The author wishes to acknowledge funding support received from the Coalition of Diverse Language Communities (CDLC) at the University of North Carolina at Greensboro. Dr. Gonzalez is an advocate for educational access for Latino youth from immigrant families in North Carolina. Her work has shifted from describing the supports and barriers encountered by these families to creating and implementing programs and interventions for them. In terms of teaching, Dr. Gonzalez dedicates her time to college counseling/student development courses at the master's level, and a theories/research course for doctoral students.

\section{References}

Auerbach, S. (2002). "Why Do They Give the Good Classes to Some and Not to Others?" Latino parent narratives of struggle in a college access program. Teachers College Record, 104, 1369-1392.

Auerbach, S. (2004). Engaging Latino parents in supporting college pathways: Lessons from a college access program. Journal of Hispanic Higher Education, 3, 125-145. https://doi.org/10.1177/1538192703262514

Auerbach, S. (2007). From moral supporters to struggling advocates: Reconceptualizing parent roles in education through the experience of working-class families of color. Urban Education, 42, 250-283. https://doi.org/10.1177/0042085907300433

Auerbach, S. (2011). Learning from Latino families. Educational Leadership, 68, 16-21. 
Bohon, S. A., Macpherson, H., \& Atiles, J. H. (2005). Educational barriers for new Latinos in Georgia. Journal of Latinos and Education, 4, 43-58. http://dx.doi.org/10.1207/s1532771xjle0401_4

Borders, L. D., Hines, E. M., Gonzalez, L. M., Villalba, J. A., \& Henderson, A. (2011). Parental involvement in college planning: A report for the College Foundation of North Carolina.

Bryan, J., \& Henry, L. (2012). A model for building school-family-community partnerships: Principles and process. Journal of Counseling \& Development, 90, 408-420. doi:10.1002/j.1556-6676.2012.00052.x

College Foundation of North Carolina (n.d.). CFNC.org: Helping you plan, apply, and pay for college. Retrieved from www.cfnc.org.

De Gaetano, Y. (2007). The role of culture in engaging Latino parents' involvement in school. Urban Education, 42, 145-162. https://doi.org/10.1177/0042085906296536

Delgado-Gaitan, C. (1991). Involving parents in schools: A process of empowerment. American Journal of Education, 100, 20-46.

Dotson-Blake, K. P. (2010). Learning from each other: A portrait of family-school-community partnerships in the United States and Mexico. Professional School Counseling, 14, 101114. https://doi.org/10.5330/prsc.14.1.e1v4q1r65t585048

Gonzalez, L. M., Villalba, J. A., \& Borders, L. D. (2015). Spanish-speaking immigrant parents and their children: Reflections on the path to college. Journal of Humanistic Counseling, 54, 122-139.

Gonzalez-Barrera, A. (2015). More Mexicans leaving than coming to U.S. Washington, DC: Pew Research Center. Retrieved from http://www.pewhispanic.org/2015/11/19/moremexicans-leaving-than-coming-to-the-u-s/

Griffin, D., \& Steen, S. (2011). A social justice approach to school counseling. Journal for Social Action in Counseling and Psychology, 3, 74-85.

Immigration Policy Center (2012). Latinos in America: A demographic overview. Retrieved from http://www.immigrationpolicy.org/just-facts/latinos-america-demographic-overview

Jasis, P. M., \& Ordoñez-Jasis, R. (2012). Latino parent involvement: Examining commitment and empowerment in schools. Urban Education, 47, 65-89. https://doi.org/10.1177/0042085911416013 
Kolb, D. A. (1984). Experiential learning: Experience as the source of learning and development (Vol. 1). Englewood Cliffs, NJ: Prentice-Hall.

Krogstad, J. M., \& Lopez, M. H. (2014). Hispanic nativity shift. Washington, DC: Pew Research Center. Retrieved from http://www.pewhispanic.org/2014/04/29/hispanic-nativity-shift/

McLester, S. (2011). The ultimate empowerment program for parents. District Administration, 47, 40-42.

Mellin, E. A., Belknap, E. E., Brodie, I. L., \& Sholes, K. (2015). Opening school doors to communities and families: A social capital perspective for multiparty collaboration. Journal for Social Action in Counseling and Psychology, 7, 1-18.

Mena, J. A. (2011). Latino parent home-based practices that bolster student academic persistence. Hispanic Journal of Behavioral Sciences, 33, 490-506. https://doi.org/10.1177/0739986311422897

Office of Community Engagement. (2012). A quick start guide to conducting community-engaged research. Los Angeles: Southern California Clinical and Translational Science Institute. Retrieved from http://oprs.usc.edu/files/2013/01/Comm_Engaged_Research_Guide.pdf

Pstross, M., Rodríguez, A., Knopf, R. C., \& Paris, C. M. (2016). Empowering Latino parents to transform the education of their children. Education and Urban Society, 48, 650-671. doi:10.1177/0013124514541464

Shea, M., Ma, P. W., \& Yeh, C. J. (2007). Development of a culturally specific career exploration group for urban Chinese immigrant youth. Career Development Quarterly, 56, 62-73. doi:10.1002/j.2161-0045.2007.tb00020.x

Storlie, C. A., \& Jach, E. A. (2012). Social justice collaboration in schools: A model for working with undocumented Latino students. Journal for Social Action in Counseling and Psychology, 4, 99-116.

Suárez-Orozco, C., Onaga, M., \& Lardemelle, C. D. (2010). Promoting academic engagement among immigrant adolescents through school-family-community collaboration. Professional School Counseling, 14, 15-26. https://doi.org/10.5330/prsc.14.1.xl6227108g624057

Tornatzky, L. G., Cutler, R., \& Lee, J. (2002). College knowledge: What Latino parents need to know and why they don't know it. Claremont, CA: Tomas Rivera Policy Institute. 
Van Velsor, P., \& Orozco, G. (2007). Involving low-income parents in the schools: Communitycentric strategies for school counselors. Professional School Counseling, 11, 17-24. https://doi.org/10.5330/PSC.n.2010-11.17

Villalba, J. A., Gonzalez, L. M., Borders, L. D., \& Hines, E. M. (2014). The Latino Parents-Learning About College (LaP-LAC) program: Educational empowerment of Latino families through psychoeducational group work. Journal for Specialists in Group Work, 39, 47-70. http://dx.doi.org/10.1080/01933922.2013.859192

Wainer, A. (2004). The New Latino South and the challenge to public education: Strategies for educators and policymakers in emerging immigrant communities. Claremont, CA: Tomas Rivera Policy Institute.

Walker, J. M., Ice, C. L., Hoover-Dempsey, K. V., \& Sandler, H. M. (2011). Latino parents' motivations for involvement in their children's schooling: An exploratory study. The Elementary School Journal, 111, 409-429. https://doi.org/10.1086/657653

Zarate, M. E. (2007). Understanding Latino parental involvement in education: Perceptions, expectations, and recommendations. Claremont, CA: Tomas Rivera Policy Institute. 